\title{
VARIABILIDADE GENÉTICA EM GENÓTIPOS DE TECA (Tectona grandis Linn. F.) BASEADA EM MARCADORES MOLECULARES ISSR E CARACTERES MORFOLÓGICOS
}

\author{
GENETIC VARIABILITY OF TEAK (Tectona grandis Linn. F.) BASED ON ISSR MOLECULAR \\ MARKERS AND MORPHOLOGICAL CHARACTERIZATION
}

\author{
Luana Della Giustina ${ }^{1}$ Ana Aparecida Bandini Rossi ${ }^{2}$ Felipe Sakamoto Vieira ${ }^{3}$ \\ Flávio Dessaune Tardin ${ }^{4}$ Leonarda Grillo Neves ${ }^{5}$ Telma Nair Santana Pereira ${ }^{6}$
}

\begin{abstract}
RESUMO
O objetivo deste estudo foi avaliar 50 genótipos de teca com base em marcadores moleculares ISSR. Dentre os genótipos estudados, 12 eram árvores candidatas, 36 vizinhas às candidatas e 02 árvores consideradas superiores com base no fenótipo, segundo a avaliação dos produtores. Esses genótipos foram propagados via seminal e possuem de 10 a 12 anos em campo. Para tal estudo foram coletadas em campo folhas jovens e expandidas de cada genótipo. O DNA total foi extraído e as amplificações foram feitas via PCR com 12 primers ISSR, previamente selecionados. As amostras foram aplicadas em gel de agarose 1,5\% e submetidas à corrida de eletroforese. Para visualização dos produtos amplificados, o gel foi corado com brometo de etídeo e fotodocumentados em transiluminador UV. Os dados foram analisados utilizando-se o programa POPGENE 1.31 e os parâmetros de diversidade foram estimados. As análises de dissimilaridade foram estimadas pelo Índice de Jaccard e a construção do dendrograma foi feita com base no método UPGMA. Paralelamente, foi realizada a análise fenotípica de dados morfológicos referentes às árvores candidatas pela análise multicategórica. Todas as análises foram realizadas com auxílio do Programa Genes. Os 12 primers amplificaram 56 fragmentos. Para o índice de conteúdos polimórfico, os iniciadores UBC 841, UBC 857 e UBC 807 proporcionaram maiores valores, 0,329, 0,327 e 0,303, respectivamente. A diversidade genética das árvores candidatas $(\mathrm{H}=0,1601 \mathrm{e} \mathrm{I}=0,2301)$ foi similar à das vizinhas $(\mathrm{H}=0,1507 ; \mathrm{I}=0,2178)$. $\mathrm{O}$ dendrograma gerado pelo método UPGMA formou 14 grupos, enquanto que no agrupamento com base em Tocher, 15 grupos foram formados. Quanto à análise fenotípica, a variável que mais contribuiu para a diversidade foi a formação de catana. Esses resultados refletem que há variabilidade entre os genótipos. Nota-se, portanto, a necessidade da ampliação da variabilidade do material, através da introdução de genótipos de diferentes procedências e não relacionados geneticamente.
\end{abstract}

Palavras-chave: diversidade genética; germoplasma; melhoramento genético.

\section{ABSTRACT}

The aim of this work was to evaluate 50 genotypes of teak based on molecular markers ISSR. Among the

1 Bióloga, MSc., Doutoranda em Biotecnologia e Biodiversidade, Universidade Federal de Mato Grosso, Av. Fernando Corrêa da Costa, 2367, Bairro Boa Esperança, CEP 78060-900, Cuiabá (MT), Brasil. lu_dellagiustina@hotmail.com

2 Bióloga, Dr ${ }^{\mathrm{a}}$., Professora da Universidade do Estado de Mato Grosso, Av. Perimetral Rogério Silva, s/n, Jardim Flamboyant, CEP 78580-000, Alta Floresta (MT), Brasil. anabanrossi@unemat.br

3 Biólogo, MSc., Professor da Educação Básica da Escola Estadual Jardim Universitário, Av. Unemat, 555, Res. Universitário, CEP 78580-000, Alta Floresta (MT), Brasil. saka_felipe@hotmail.com

4 Engenheiro Agrônomo, Dr., Pesquisador A da Empresa Brasileira de Pesquisa Agropecuária, Rod. MT 222, KM 2,5, CEP 78550-970, Sinop (MT), Brasil. flavio.tardin@embrapa.br

5 Engenheira Agrônoma, Dra ${ }^{\mathrm{a}}$., Professora da Universidade do Estado de Mato Grosso. Av. Santos Dumond, s/n, Bairro Santos Dumond, CEP 78200-000, Cáceres (MT), Brasil. leonardaneves@unemat.br

6 Engenheira agrônoma, PhD., Professora da Universidade Estadual do Norte Fluminense Darcy Ribeiro, Av. Alberto Lamego, 2000, CEP 28013-602, Campos dos Goytacazes (RJ), Brasil. telmasp2012@gmail.com

Recebido para publicação em 10/04/2014 e aceito em 15/08/2016 
genotypes studied, 12 were candidate trees, 36 were surrounding the candidates and 02 trees were considered superior based on the phenotype, according to the assessment of the producers. These genotypes were propagated through seminal via and are 10 to 12 years old in the field. For this study, young and expanded leaves of each genotype were collected in the field. Total DNA was extracted and the amplifications were made by PCR with 12 primers ISSR, previously selected. The samples were applied in agarose gel $1.5 \%$ and subjected to electrophoresis running. For visualization of the amplified products, the gel was stained with ethidium bromide and photodocumented in UV transilluminator. Data were analyzed using the program POPGENE 1.31 and diversity parameters were estimated. Dissimilarity analyzes were estimated by Jaccard Index and the dendrogram construction was made based on the UPGMA method. At the same time, the phenotypic analysis of morphological data regarding the candidate trees was conducted by multicategorical analysis. All analyzes were performed with the assistance of Genes Program. The 12 primers amplified 56 fragments. For polymorphic information content the indicators UBC 841, UBC 857 and UBC 807 provided higher values, $0.329,0.327$ and 0.303 , respectively. The genetic diversity of the candidate trees $(\mathrm{H}=0.1601$ and $\mathrm{I}=0.2301)$ was similar to the neighbors $(\mathrm{H}=0.1507, \mathrm{I}=0.2178)$. The dendrogram generated by the UPGMA method formed 14 groups, while the grouping based on Tocher, 15 groups were formed. For the phenotypic analysis, the variable that most contributes to the diversity was the formation of catana. These results reflect that there is variability among the genotypes. It is possible to note, therefore, the need to expand the variability of the material, by introducing genotypes of different origins and genetically unrelated.

Keywords: genetic diversity; germplasm; breeding.

\section{INTRODUÇÃO}

Teca (Tectona grandis Linn. F.) pertence à família Lamiaceae e possui alto valor econômico devido às características de sua madeira (RONDON NETO; MACEDO; TSUKAMOTO-FILHO et al., 1998). Ocorre naturalmente na Índia Peninsular, Myanmar, Laos e Tailândia (TROUP, 2006). Dentre as espécies arbóreas e exóticas plantadas no Brasil, a espécie destaca-se como a mais promissora para o plantio nas regiões sudeste e centro-oeste (ASSOCIAÇÃO BRASILEIRA DE PRODUTORES DE FLORESTAS PLANTADAS, 2009).

Por ser uma espécie exótica, a falta de inimigos naturais, provavelmente seja o motivo de sua boa adaptação, destacando-se entre espécies nativas como o mogno (Swietenia macrophylla King.) e o cedro (Cedrella odorata L.) que são susceptíveis a doenças, desta forma, a teca é utilizada com sucesso em áreas de pastagens ou florestas secundárias em fase inicial de sucessão ecológica (FIGUEIREDO, 2001). Os reflorestamentos de teca atualmente abrangem estados como o Amazonas, Acre, Pará e Rondônia (FIGUEIREDO, 2001; VIEIRA et al., 2001). Além disso, esta espécie representa uma nova alternativa florestal atrativa para a região mato-grossense.

Áreas de plantios comerciais de teca no Brasil ocupam 67.693 ha, sua madeira é destinada principalmente para construção civil, assoalhos e decks, móveis, embarcações e lâminas decorativas (ASSOCIAÇÃO BRASILEIRA DE PRODUTORES DE FLORESTAS PLANTADAS, 2012). No final da década de 60 iniciaram-se os plantios na região de Cáceres - MT, pela empresa Cáceres Florestal S.A., neste local, as condições climáticas assemelham-se ao país de origem da espécie (MATRICARD, 1989). Porém, condições favoráveis como clima, solo, traços silviculturais, contribuíram para reduzir o ciclo de produção da teca de 80 para 25 anos comparados com sua região de origem (TSUKAMOTO-FILHO et al., 2003). Na Ásia, o seu ciclo de rotação é variável de 60 a 100 anos (UGALDE; PÉREZ, 2001).

Estudos citogenéticos caracterizam a teca como diploide $(2 \mathrm{n}=2 \mathrm{x}=36$ cromossomos $)$ (GILL; BEDI; BIR, 1983; KERTADIKARA; PRAT, 1995), monoica e polinizada por insetos (BRYNDUM; HEDEGART, 1969; HEDEGART, 1973; MATHEW; MATHEW; MOHANADAS, 1987). Aos seis anos inicia-se a frutificação, mas já foram registrados casos precoces com plantas florescendo aos dois ou três anos de idade (JOSÉBIO; VENTURIM; GOMES, 2007). A teca é uma espécie predominantemente alógama, com taxa de cruzamento da ordem de 95\% a 98\% (KERTADIKARA; PRAT, 1995). Assim, as estratégias de melhoramento empregadas rotineiramente em outras espécies florestais 
alógamas (RESENDE, 1999) podem ser aplicadas à espécie.

Os custos do melhoramento florestal em teca são elevados, devido à baixa capacidade de frutificação e de germinação das sementes (KJAER; FOSTER, 1996; KAOSA-ARD; SUANGTHO; KJAER, 1998). Projetos de melhoramento com teca já estão disponíveis em países como Tailândia, Malásia, Tanzânia, Índia, Indonésia e Costa Rica (SCHUHLI; PALUDZYSZYN FILHO, 2010).

Segundo Schuhli e Paludzyszyn Filho (2010), o desenvolvimento de estratégias para o aumento da produção de sementes e mudas com qualidade e em quantidade suficientes para garantir a demanda do mercado crescente para teca no Brasil, é importante para futuros programas de melhoramento. De forma geral, a seleção de genótipos em teca é realizada com base em características fenotípicas. Assim, produtores bem como pesquisadores do Estado de Mato Grosso (Bacaeri Florestal Ltda.) selecionaram genótipos de teca que se destacaram em populações cultivadas, porém, a expressão fenotípica é resultado da interação do genótipo com o ambiente.

Segundo Fonseca e Ribeiro (1992), a caracterização morfológica juntamente à molecular propicia um melhor conhecimento dos recursos genéticos e auxilia para a seleção de populações e/ou plantas com características desejáveis para o cultivo. Ainda, os marcadores moleculares permitem gerar uma grande quantidade de informações sobre a diversidade genética do germoplasma utilizado pelo melhorista (FERREIRA; GRATTAPAGLIA, 1996).

Dentre os marcadores moleculares, o ISSR (Inter Simple Sequence Repeat) é baseado em PCR e tem se destacado como uma alternativa eficiente para caracterização de genomas complexos. Foi desenvolvido a partir da necessidade de explorar repetições microssatélites sem a utilização de sequenciamento do DNA (ZIETKIEWICZ; RAJALSKI; LABUDA, 1994). A reação de PCR-ISSR é uma técnica simples, rápida, de baixo custo, eficiente e que não requer informação prévia da sequência de DNA do organismo em estudo. O tamanho dos fragmentos amplificados varia de $200 \mathrm{a} 2000 \mathrm{pb}$ e apresentam alta reprodutibilidade, devido, possivelmente, ao uso de iniciadores longos (16 a 25 pares de bases) que são capazes de, em uma única reação de PCR, reconhecer múltiplos loci no genoma para amplificar principalmente as sequências intermicrossatélites de diferentes tamanhos (ZIETKIEWICZ; RAJALSKI; LABUDA, 1994).

Produtores da Fazenda Bacaerí Florestal Ltda., Alta Floresta - MT, cultivam a teca desde 1996 e nestes cultivos selecionaram genótipos de teca denominados de "árvores candidatas" e "árvores vizinhas" das árvores candidatas, as quais vêm sendo avaliadas com base em características fenotípicas desejáveis para a produção de madeira, tais como, diâmetro a altura do peito e altura total, visando à seleção de genótipos superiores para produção de mudas em viveiros, por meio de propagação vegetativa.

Neste contexto, o objetivo do presente estudo foi avaliar a variabilidade genética das árvores de teca selecionadas (candidatas e vizinhas) pelos produtores da Fazenda Bacaerí Florestal Ltda., MT, por meio de marcadores ISSR e por meio de características morfológicas.

\section{MATERIAL E MÉTODOS}

\section{Material vegetal}

A área de estudo compreende um plantio comercial de 1.200 hectares, com aproximadamente 1.200.000 árvores, na Fazenda Bacaeri Florestal Ltda. (BAC) localizada no município de Alta Floresta MT (9 $\left.56^{\prime} 49.01^{\prime \prime} \mathrm{S} ; 56^{\circ} 55^{\prime} 01.16^{\prime \prime} \mathrm{W}\right)$. O plantio foi iniciado a partir de sementes da espécie.

O plantio comercial está dividido em 32 talhões. Em 13 destes talhões, os indivíduos possuem idades superiores a 11 anos, dentre os quais foram selecionados 50 genótipos para o presente estudo. A escolha dos genótipos foi realizada pelos produtores com base em características fenotípicas, levando em consideração características desejáveis para uso da madeira, sendo o principal o diâmetro a altura do peito (DAP).

Dentre esses 50 genótipos selecionados, 12 são árvores designadas como candidatas, 36 árvores vizinhas das candidatas e duas plantas chamadas de Namorada e Solteirona (Tabela 1). As árvores candidatas, segundo a avaliação dos produtores, são genótipos que se destacaram nos talhões em relação às características fenotípicas avaliadas. Para cada árvore candidata foram escolhidas árvores vizinhas. A 
TABELA 1: Relação dos 50 genótipos de teca selecionados pelos produtores da Fazenda Bacaerí Florestal Ltda. de Alta Floresta - MT, avaliados neste estudo.

TABLE 1: List of 50 genotypes selected by producers from the teak Farm 'Bacaerí Florestal Ltda.', in Alta Floresta, MT state, evaluated in this study.

\begin{tabular}{|c|c|c|c|}
\hline Genótipo & Sigla & Genótipo & Sigla \\
\hline Solteirona & BAC 1 & T9 C1 & BAC 49 \\
\hline Namorada & BAC 2 & $\mathrm{~T} 2 \mathrm{C} 2$ & BAC 50 \\
\hline $\mathrm{T} 1 \mathrm{C} 1$ & BAC 26 & $\mathrm{~T} 2 \mathrm{C} 2 \mathrm{~V} 1$ & BAC 51 \\
\hline $\mathrm{T} 1 \mathrm{C} 1 \mathrm{~V} 1$ & BAC 27 & $\mathrm{~T} 2 \mathrm{C} 2 \mathrm{~V} 2$ & BAC 52 \\
\hline $\mathrm{T} 1 \mathrm{C} 1 \mathrm{~V} 2$ & BAC 28 & $\mathrm{~T} 2 \mathrm{C} 2 \mathrm{~V} 3$ & BAC 53 \\
\hline T1 C1 V3 & BAC 29 & $\mathrm{~T} 2 \mathrm{C} 2 \mathrm{~V} 4$ & BAC 54 \\
\hline $\mathrm{T} 1 \mathrm{C} 1 \mathrm{~V} 4$ & BAC 30 & $\mathrm{~T} 2 \mathrm{C} 3$ & BAC 55 \\
\hline $\mathrm{T} 1 \mathrm{C} 2$ & BAC 31 & $\mathrm{~T} 2 \mathrm{C} 3 \mathrm{~V} 1$ & BAC 56 \\
\hline $\mathrm{T} 1 \mathrm{C} 2 \mathrm{~V} 1$ & BAC 32 & $\mathrm{~T} 2 \mathrm{C} 3 \mathrm{~V} 2$ & BAC 57 \\
\hline $\mathrm{T} 1 \mathrm{C} 2 \mathrm{~V} 4$ & BAC 33 & $\mathrm{~T} 2 \mathrm{C} 3 \mathrm{~V} 3$ & BAC 58 \\
\hline $\mathrm{T} 1 \mathrm{C} 3$ & BAC 34 & $\mathrm{~T} 2 \mathrm{C} 3 \mathrm{~V} 4$ & BAC 59 \\
\hline T1 C3 V1 & BAC 35 & T4 C3 & BAC 60 \\
\hline T1 C3 V2 & BAC 36 & T4 C3 V1 & BAC 61 \\
\hline T1 C3 V3 & BAC 37 & T4 C3 V2 & BAC 62 \\
\hline T1 C3 V4 & BAC 38 & T4 C3 V3 & BAC 63 \\
\hline $\mathrm{T} 1 \mathrm{C} 4$ & BAC 39 & $\mathrm{~T} 4 \mathrm{C} 4$ & BAC 65 \\
\hline T1 C4 V1 & BAC 40 & T4 C4 V1 & BAC 66 \\
\hline $\mathrm{T} 1 \mathrm{C} 4 \mathrm{~V} 2$ & BAC 41 & $\mathrm{~T} 4 \mathrm{C} 4 \mathrm{~V} 2$ & BAC 67 \\
\hline $\mathrm{T} 1 \mathrm{C} 4 \mathrm{~V} 3$ & BAC 42 & $\mathrm{~T} 4 \mathrm{C} 4 \mathrm{~V} 3$ & BAC 68 \\
\hline $\mathrm{T} 1 \mathrm{C} 4 \mathrm{~V} 4$ & BAC 43 & T4 C4 V4 & BAC 69 \\
\hline $\mathrm{T} 2 \mathrm{C} 1$ & BAC 44 & T6 C1 & BAC 70 \\
\hline $\mathrm{T} 2 \mathrm{C} 1 \mathrm{~V} 1$ & BAC 45 & T6 C1 V1 & BAC 71 \\
\hline $\mathrm{T} 2 \mathrm{C} 1 \mathrm{~V} 2$ & BAC 46 & T6 C1 V3 & BAC 72 \\
\hline $\mathrm{T} 2 \mathrm{C} 1 \mathrm{~V} 3$ & BAC 47 & T6 C1 V4 & BAC 73 \\
\hline $\mathrm{T} 2 \mathrm{C} 1 \mathrm{~V} 4$ & BAC 48 & $\mathrm{~T} 13 \mathrm{C} 1$ & BAC 74 \\
\hline
\end{tabular}

Em que: $\mathrm{T}=$ Talhão; $\mathrm{C}=$ Candidata; $\mathrm{V}=$ Vizinha da candidata; $\mathrm{BAC}=$ Bacaeri.

Namorada e a Solteirona, foram incluídas nas análises devido aos seus altos valores de DAP e altura total. São genótipos, considerados superiores de acordo com a avaliação dos produtores para a comercialização da madeira.

As plantas foram propagadas via seminal, sendo que o plantio do talhão 9 foi realizado em dezembro de 1996 com espaçamento de 2 x 3 m. O plantio dos talhões 1 e 2 foi efetuado em janeiro de 1998 com espaçamento de $4 \times 4 \mathrm{~m}$. As plantas dos talhões 6,13 e 4 foram plantadas com o mesmo espaçamento de 3 x 3 m, porém, em diferentes anos, o talhão 6 em fevereiro de 1998, o talhão 13 em novembro de 1999 e o talhão 4 em janeiro de 2000.

Em relação aos tratos culturais são realizadas as podas de condução, formação e correção, e os desbastes sanitário, espacial e de forma, em um período de 3 a 5 anos. Durante os desbastes são retiradas aquelas plantas que apresentam características indesejáveis na avaliação dos produtores.

\section{Extração e quantificação de DNA}

Foram coletadas folhas jovens, expandidas e sadias de cada um dos 50 genótipos selecionados. 
Cada folha, isoladamente, foi envolta em papel-alumínio e congelada para o transporte da Fazenda ao Laboratório de Genética do campus Universitário de Alta Floresta - UNEMAT, onde foram armazenadas até uso posterior.

O DNA genômico foi extraído de aproximadamente $100 \mathrm{mg}$ de folhas, segundo o método CTAB descrito por Doyle e Doyle (1990) modificado com base em Alcântara, Siqueira e Veasey (2008). A qualidade e a concentração do DNA extraído foram confirmadas por eletroforese em gel de agarose $0,8 \%$. A concentração foi comparada através de pesos moleculares de DNA padrão (lambda) com amplitude de variação de 10, 20, 50 e $100 \mathrm{ng}$. O DNA quantificado foi diluído para a obtenção das soluções de trabalho ( $\pm 20 \mathrm{ng})$.

\section{Seleção de primers ISSR e reações de amplificação}

Inicialmente, foram realizados testes de amplificação em três genótipos de teca com 34 primers ISSR desenvolvidos pela University of British Columbia (UBC). Com base nos padrões de bandeamento para intensidade, polimorfismo e repetitividade, foram selecionados 12 dos 34 primers testados. As reações de amplificação via PCR foram realizadas em termociclador Biocycler com um volume final de $20 \mu \mathrm{L}$, sendo $1 \mu \mathrm{L}$ de DNA ( $\pm 20 \mathrm{ng}), 2 \mu \mathrm{L}$ de tampão $10 \mathrm{x}(1 \mathrm{M} \mathrm{KCl} ; 1 \mathrm{M}$ Tris $\mathrm{pH} 8.3 ; 10 \%$ Tween 20$), 2 \mu \mathrm{L}$ de $\mathrm{MgCl}_{2}(25 \mathrm{mM}), 3 \mu \mathrm{L}$ de primer $(0,2 \mathrm{mM}), 4 \mu \mathrm{L}$ dNTP $(0,1 \mathrm{mM}$ de cada dNTP $), 1 \mu \mathrm{L}$ DMSO e $0,2 \mu \mathrm{L}$ de taq polimerase $(5 \mathrm{U} / \mu 1)$. O programa de amplificação foi proposto por Narayanan et al. (2006) sendo: um ciclo de desnaturação de $94^{\circ} \mathrm{C}$ por $3 \mathrm{~min} ; 30$ ciclos de $94^{\circ} \mathrm{C}$ por $30 \mathrm{~s}, 45-53^{\circ} \mathrm{C}$ (dependendo da temperatura do primer) por $30 \mathrm{~s} \mathrm{e} 72^{\circ} \mathrm{C} 1 \mathrm{~min}$; um ciclo de extensão final de $72^{\circ} \mathrm{C}$ por $10 \mathrm{~min}$.

Os produtos de amplificação foram separados por eletroforese em gel de agarose 1,5\% em tampão de corrida TBE $1 \mathrm{X}$, com voltagem constante de $85 \mathrm{~V}$ por aproximadamente quatro horas. Os tamanhos dos fragmentos amplificados foram estimados, por comparação, com o marcador molecular de 100 pb DNA Ladder. A coloração do gel foi realizada com brometo de etídeo $\left(0,6 \mathrm{ng} \mathrm{mL}^{-1}\right)$. Em seguida os géis foram visualizados em transiluminador UV e fotodocumentados.

\section{Caracterização fenotípica}

A caracterização fenotípica dos 50 genótipos em estudo foi realizada de acordo com as características avaliadas pelos produtores. As variáveis analisadas foram:

1. Altura total da planta (m) (AT),

2. Altura até a primeira bifurcação $(\mathrm{m})(\mathrm{AB})$,

3. Diâmetro a altura do peito $(\mathrm{cm})(\mathrm{DAP})$,

4. Qualidade dos ramos (QR). Os ramos foram avaliados com notas de 1-6 conforme sua espessura, o ângulo de inserção, grossura e quantidade. Nota 1 pior ramo e nota 6 melhor ramo.

5. Qualidade das toras 1, 2 e 3 (QT1; QT2; QT3). As toras foram nomeadas de 1-3 a cada 2,5 m a partir do solo. Foram atribuídas notas de 1-6 as toras de acordo com a presença de envaginamento, nós e tronco cilíndrico. Nota 1 pior tora e nota 6 melhor tora.

6. Formação de catana (FC). Foram atribuídas notas de 1-6. Quanto maior a altura $(\mathrm{cm})$ da catana menor a sua nota. Nota 1 pior e nota 6 melhor.

\section{Análise estatística}

Os fragmentos de ISSR (produtos de amplificação) foram analisados e codificados como caracteres binários: presença (1) ou ausência (0) de bandas.

Para obtenção da matriz de dissimilaridade foi utilizado o complemento aritmético do Índice de Jaccard. Este coeficiente é definido pela expressão: 


$$
\begin{aligned}
& \mathrm{Dij}=1-\mathrm{Sij} \\
& \mathrm{Sij}=\frac{a}{a+b+c}
\end{aligned}
$$

Em que:

$\mathrm{a}=$ número de bandas presentes nos acessos $\mathrm{i}, \mathrm{j}$;

$\mathrm{b}=$ número de bandas presentes no acesso i e ausentes no acesso $\mathrm{j}$;

$\mathrm{c}=$ número de bandas presentes no acesso $\mathrm{j}$ e ausentes no acesso $\mathrm{i}$.

A matriz de distâncias geradas pelo coeficiente aritmético do Índice de Jaccard foi utilizada para o agrupamento dos genótipos pelo método de otimização de Tocher. Os genótipos também foram agrupados por um dendrograma pelo método UPGMA (Unweighted Pair Group Method with Arithmetic mean). As matrizes de dissimilaridade geradas e os agrupamentos (UPGMA e Tocher) foram computados com o auxílio do programa Genes ${ }^{\circledR}$ (CRUZ, 2008).

O programa POPGENE 1.31 (YEH; YANG; BOYLE, 1999) foi utilizado para estimar os parâmetros de diversidade através dos índices de Shannon (I) e de Nei $(\mathrm{H})$, os quais variam de 0 a 1 , com valores mais próximos de zero $(0)$ menor será a diversidade genética.

A diversidade genética do loco foi estimada com base no Indice de Conteúdo Polimórfico (PIC) (REZENDE et al., 2009) que é uma estimativa utilizada para a avaliação do poder discriminatório de um loco, calculado pela equação:

$$
\mathrm{PIC}=1-\Sigma_{\mathrm{i}} \mathrm{p}_{\mathrm{i}}^{2}
$$

Em que: a informatividade do loco $\mathrm{p}_{\mathrm{i}}$ é a frequência do alelo $\mathrm{p}$ no $l o c o \mathrm{p}_{\mathrm{i}}$, e a informatividade do primer $\mathrm{p}_{\mathrm{ij}}$ é a frequência do alelo $\mathrm{p}$ do loco i, no primer j, sendo calculada pela equação:

$$
\text { PIC primer }=1-\Sigma_{\mathrm{i}} \cdot \Sigma_{\mathrm{j}} \mathrm{p}_{\mathrm{ij}}^{2}
$$

Os dados fenotípicos foram analisados através da matriz de dissimilaridade pelas variáveis multicategóricas as quais agregaram dados quantitativos e qualitativos e também pelas análises de componentes principais com o auxílio do programa Genes ${ }^{\circledR}$ (CRUZ, 2008).

\section{RESULTADOS E DISCUSSÃO}

Os 12 primers ISSR amplificaram um total de 56 fragmentos nos 50 genótipos de teca analisados, sendo 22 bandas polimórficas $(39,3 \%)$. A média de bandas amplificadas por primer foi de 4,66. Os primers que revelaram maior percentual de polimorfismo foram UBC 861 e UBC 834 com $75 \%$ e 50\%, respectivamente (Tabela 2 ).

Ansari et al. (2012) ao estudarem 29 populações naturais de teca com base em marcadores ISSR, encontraram uma média de 8,6 bandas por primer, em contraste ao encontrado no presente estudo que foi de 4,66 bandas por primer. Enquanto Ansari et al. (2012) utilizaram 5 marcadores em suas análises, para este trabalho 12 marcadores foram utilizados.

O Conteúdo de Informação Polimórfica (PIC) para cada marcador apresentou variação de 0,057 (UBC 827) a 0,329 (UBC 841), com média de 0,204. Os primers UBC 841, UBC 857 e UBC 807 demonstraram maiores valores de PIC com 0,329, 0,327, 0,303, respectivamente (Tabela 2).

Segundo a classificação de Botstein et al. (1980), marcadores com valores de PIC superiores a 0,5 são considerados muito informativos, valores entre 0,25 e 0,50 , mediamente informativos, e valores inferiores a 0,25 , pouco informativos. O PIC representa a existência de variabilidade, a qual será maior com 
TABELA 2: Código do primer, sequência de anelamento, TM = Temperatura de anelamento referente ao primer, número total de bandas, percentual de polimorfismo e valor do PIC, a partir dos 50 genótipos de teca analisados.

TABLE 2: Primer code, following annealing, TM = Annealing temperature references primer total number of bands, percentage of polymorphism and PIC value, from 50 teak genotypes analyzed.

\begin{tabular}{lccccc}
\hline \multicolumn{1}{c}{ Primer } & Sequência do Primer $\left(5^{\prime}-3^{\prime}\right)$ & $\begin{array}{c}\text { TM } \\
\left({ }^{\circ} \mathrm{C}\right)\end{array}$ & $\begin{array}{c}\text { N. de } \\
\text { Bandas }\end{array}$ & $\begin{array}{c}\text { \% de } \\
\text { Polimorfismo }\end{array}$ & PIC 1 \\
\hline UBC 807-DiAG(T) & AGAGAGAGAGAGAGAGT* & 47 & 3 & 33,33 & 0,303 \\
UBC 810-DiGA(T) & GAGAGAGAGAGAGAGAT* & 45,4 & 3 & 33,33 & 0,246 \\
UBC 826-DiAC(C) & ACACACACACACACACC & 53 & 7 & 42,86 & 0,243 \\
UBC 827-DiAC(G) & ACACACACACACACACG & 53 & 7 & 28,57 & 0,057 \\
UBC 828-DiTG(A) & TGTGTGTGTGTGTGTGA & 52 & 7 & 42,86 & 0,153 \\
UBC 830-DiTG(G) & TGTGTG TGT GTG TGT GG & 52 & 5 & 20,00 & 0,060 \\
UBC 834-DiAG(YT) & AGAGAGAGAGAGAGAGYT* & 49 & 4 & 50,00 & 0,118 \\
UBC 835-DiAG(YC) & AGAGAGAGAGAGAGAGYC* & 50,2 & 3 & 33,33 & 0,192 \\
UBC 840-DiGA(YC) & GAGAGAGAGAGAGAGAYT* & 50 & 5 & 40,00 & 0,154 \\
UBC 841-DiGA(YC) & GAGAGAGAGAGAGAGAYC* & 50 & 3 & 33,33 & 0,329 \\
UBC 857-DiAC(YG) & ACACACACACACACACYG* & 50 & 5 & 40,00 & 0,327 \\
UBC 861 - TriACC & ACCACCACCACCACCACC & 60,6 & 4 & 75,00 & 0,266 \\
\hline & & & 4,66 & 39,38 & 0,204
\end{tabular}

Em que: $\mathrm{Y}=\mathrm{C}$ ou T; $\mathrm{R}=\mathrm{A}$ ou G; V = A, C ou G; H = A, C ou T. 1= Índice de Conteúdo Polimórfico.

valores mais altos de PIC. Assim, marcadores ISSR que apresentam essa característica são os mais indicados para estudos de variabilidade (RIBEIRO, 2011). Dos 12 marcadores utilizados, quatro apresentaram o PIC acima de 0,25 [UBC 807 (PIC = 0,303), UBC 841(PIC=0,329), UBC 857 (PIC =0,327) e UBC 861 $(\mathrm{PIC}=0,266)]$, sendo, portanto, os mais recomendados para análise da diversidade em teca.

Os índices de diversidade estimados a partir de Nei $(\mathrm{H})$ e de Shannon (I) das plantas candidatas foram de $\mathrm{H}=0,1601$ e $\mathrm{I}=0,2301$, muito próximos dos valores encontrados para as árvores vizinhas das candidatas $(\mathrm{H}=0,1507 ; \mathrm{I}=0,2178)$. Revelando, assim, que os dois grupos selecionados pelos produtores em suas plantações apresentaram índices de diversidade próximos e a mesma porcentagem de polimorfismo $(37,5 \%)$ (Tabela 3$)$.

Os marcadores moleculares ISSR revelaram variabilidade genética entre os genótipos de teca analisados. Como esses indivíduos são originários de plantas oriundas de sementes, e a teca é uma espécie alógama, era esperado uma maior diversidade genética no material.

Como o sistema reprodutivo por alogamia possibilita que maiores variabilidades sejam encontradas dentro de populações, uma vez que favorece a recombinação (HARTL, 2008), uma hipótese para a baixa variabilidade encontrada entre os genótipos avaliados é a procedência do material cultivado (material já selecionado), pois, com os ciclos seletivos, a variabilidade vai decrescendo pela diminuição da frequência

TABELA 3: Diversidade genética dos genótipos de teca estimados via índice diversidade gênica de Nei (H) e índice de diversidade gênica de Shannon (I) e porcentagem de polimorfismo (\%P).

TABLE 3: Genetic diversity of genotypes teak estimated via Nei's gene diversity index $(\mathrm{H})$, gene diversity Shannon index (I) and percentage of polymorphism (\%P).

\begin{tabular}{lccc}
\hline \multicolumn{1}{c}{ Grupos } & $\mathrm{H}$ & $\mathrm{I}$ & $\% \mathrm{P}$ \\
\hline Árvores Vizinhas & 0,1507 & 0,2178 & 37,50 \\
Árvores Candidatas & 0,1601 & 0,2301 & 37,50 \\
Vizinhas/Candidatas & 0,1575 & 0,2288 & 39,29 \\
\hline
\end{tabular}


de indivíduos heterozigotos. Ansari et al. (2012) avaliando 29 populações naturais de teca de diferentes regiões da Índia, com ISSR, encontraram maiores índices de diversidade do que os encontrados neste estudo, reforçando assim, que a variabilidade genética de materiais naturais de teca são maiores.

A caracterização da variabilidade genética de uma espécie é essencial para o sucesso de um programa de melhoramento genético. Segundo Schulli e Paludzyszyn Filho (2010), estudos de diversidade genética em teca no Brasil são restritos, esta carência de conhecimento pode estar limitando seu cultivo e dificultando o avanço em programas de melhoramento.

O complemento aritmético do Índice de Jaccard foi empregado na matriz, de dados binários, formada a partir dos 60 fragmentos gerados. O valor do coeficiente de correlação cofenética (r) foi de 0,61. A máxima distância observada foi entre os genótipos BAC 54 e BAC 59 (Dij = 0,268) sendo, portanto, os materiais mais divergentes neste estudo. A mínima distância foi entre os genótipos BAC 51 com BAC 68 e BAC 52 com BAC $53(\mathrm{Dij}=0)$ sendo assim os mais similares, não podendo ser distinguidos geneticamente com os marcadores utilizados nesta análise. A distância média entre os genótipos foi de 0,139 .

O dendrograma gerado com base no UPGMA entre os 50 genótipos analisados formou 14 grupos, considerando o ponto de corte 0,60 (Figura 1 ).

O grupo I alocou 9 genótipos $(51,68,67,66,69,70,63,47,48)$, o grupo II quatro genótipos $(1,2,71$ e 72), o grupo III foi formado por três genótipos (41, 42 e 34), o grupo IV também com três genótipos (29, 35 e 38), o grupo V com 10 genótipos $(26,36,28,44,40,43,39,73,27$ e 37), o grupo VI composto por três genótipos (54, 55 e 56), o grupo VII foi formado por dois genótipos (49 e 74), o grupo VIII agrupou quatro genótipos (52, 53, 60 e 50), no grupo IX estão agrupados dois genótipos (45 e 46), o grupo XI com dois genótipos (31 e 32), o grupo XIII com cinco (61, 62, 65, 59 e 58) e os grupos X, XII, e XIV foram representados por um genótipo cada, sendo 30, 33 e 57, respectivamente.

Os doze genótipos que foram selecionados como árvores candidatas não ficaram distribuídos em grupo distintos, o que era esperado, uma vez que há uma origem em comum das sementes que foram utilizadas para compor o plantio. Porém, houve a formação de 14 grupos diferentes, revelando que os materiais não são idênticos, geneticamente.

O método de agrupamento de Tocher possibilitou a formação de 15 grupos (Tabela 4) a partir das bandas geradas pelos marcadores ISSRs. Os genótipos selecionados como árvores candidatas alocaram-se em grupos distintos, com exceção dos genótipos BAC 39 e BAC 60 que permaneceram no mesmo grupo. A formação de grupos individuais ocorreu com frequência (seis grupos).

Quanto aos dados fenotípicos, os genótipos BAC 56, BAC 57 e BAC 72, que são árvores vizinhas às candidatas, apresentam altos valores de diâmetro a altura do peito (DAP $=120,120$ e 115, respectivamente), característica desejável em plantios que visem à produção de madeira. Como estes genótipos formaram grupos isolados são genótipos promissores para serem incluídos na avaliação a fim de serem futuras árvores candidatas.

Ambos os métodos de agrupamento, Tocher e UPGMA, proporcionaram a formação de grupos semelhantes com base nos 50 genótipos de teca avaliados.

*Em destaque, árvores candidatas selecionadas pelos produtores.

$\mathrm{Na}$ Tabela 5 estão descritos os valores das variáveis fenotípicas avaliadas nos 50 genótipos de teca. As árvores candidatas apresentam uma média de $133 \mathrm{~cm}$ para a variável diâmetro a altura do peito (DAP) e $22 \mathrm{~m}$ para altura total (AT). As árvores vizinhas das candidatas obtiveram como médias, DAP $=117 \mathrm{~cm}$ e $\mathrm{AT}=21 \mathrm{~m}$. Os genótipos mais promissores com base nas características fenotípicas foram BAC 01 e BAC 02 que apresentam um DAP de $176 \mathrm{~cm}$ e $173 \mathrm{~cm}$, respectivamente, e AT de 26 metros.

Na Tabela 6 estão discriminados os valores e os coeficientes de ponderação das oito características fenotípicas analisadas. Considerando que a importância relativa dos caracteres na divergência genética é determinada pelas variáveis com maiores pesos nos últimos autovetores, neste estudo, a característica DAP das árvores de teca foi a de menor importância para discriminar a diversidade genética por componentes principais.

A variável a partir dos dados fenotípicos que melhor contribuiu na representação da diversidade dos acessos de teca foi a formação de catana (FC) com 21,28\% seguida das demais variáveis, qualidade da tora 2 (QT2), qualidade da tora 1 (QT1), qualidade da tora 3 (QT3), qualidade dos ramos (QR), altura total (AT), altura até a primeira bifurcação $(\mathrm{AB})$ e DAP (tabela 7). 


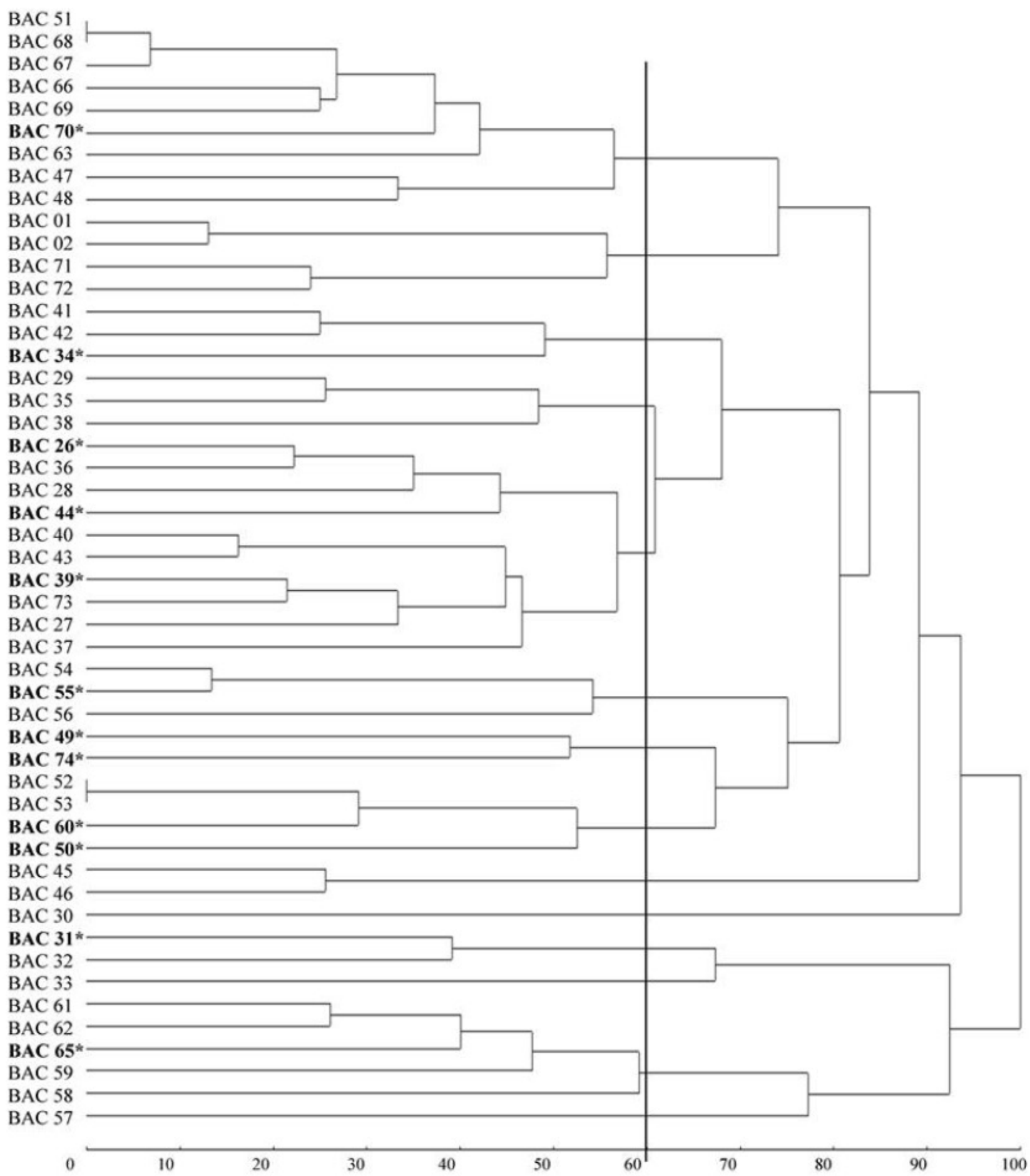

FIGURA 1: Dendrograma gerado usando o método UPGMA mostrando as relações entre os 50 genótipos de teca com base nos marcadores ISSR.*Árvores candidatas.

FIGURE 1: Dendrogram generated using UPGMA method showing the relationships among 50 genotypes teak based on ISSR markers. 
TABELA 4: Agrupamento dos 50 genótipos de teca pelo método Tocher, a partir da análise molecular por meio dos marcadores ISSR.

TABLE 4: Grouping of 50 genotypes teak by Tocher's method from the molecular analysis using ISSR markers.

\begin{tabular}{|c|c|}
\hline Grupos & Genótipos \\
\hline \multirow{2}{*}{ I } & BAC 51;BAC 67;BAC 68;BAC 66;BAC 69;BAC 70*;BAC 73;BAC 63; \\
\hline & BAC $71 ;$ BAC $60 *$ BAC $39 *$ BAC 53 \\
\hline \multirow{2}{*}{ II } & BAC $01 ; \mathrm{BAC} 02 ; \mathrm{BAC} 37 ; \mathrm{BAC} 26^{*} ; \mathrm{BAC} 35 ; \mathrm{BAC} 38 ; \mathrm{BAC} 36$; BAC 28 ; \\
\hline & BAC $44 *$;BAC 27;BAC 40 \\
\hline III & BAC 54;BAC 55*;BAC 43 \\
\hline IV & BAC $41 ;$ BAC $42 ;$ BAC $34 *$ BAC $49 *$ \\
\hline $\mathrm{V}$ & BAC 45 ; BAC 46 ; BAC 47 ; BAC 48 \\
\hline VI & BAC $61 ;$ BAC 62 ; BAC $65^{*}$; BAC 59 \\
\hline VII & BAC $31 *$; BAC 32 \\
\hline VIII & BAC $50^{*} ;$ BAC 52 \\
\hline IX & BAC 29; BAC33 \\
\hline $\mathrm{X}$ & BAC 30 \\
\hline XI & BAC 56 \\
\hline XII & BAC 57 \\
\hline XIII & BAC 58 \\
\hline XIV & BAC 74* \\
\hline $\mathrm{XV}$ & BAC 72 \\
\hline
\end{tabular}

A formação de catana tem influência principalmente sob a qualidade da tora 1 . A tora 1 possui maior valor comercial devido aos valores do volume da madeira. Os genótipos BAC 01 e BAC 02, os quais apresentam altos valores de DAP, e AT possuem a formação de catana. Podendo assim, explicar a importância desta característica (FC) em relação a sua contribuição para a representação dos dados.

A candidata BAC 44 não apresenta formação de catana e suas notas para QT1, QT2, QT3 e FC são 4; 6; 6; 5 e 6, respectivamente, além de $153 \mathrm{~cm}$ de DAP, sendo a candidata com maiores valores depois de BAC 01 e BAC 02 .

Com base nas análises fenotípicas e moleculares dos genótipos BAC 01 e BAC 02 sugere-se a escolha de apenas um para compor o quadro de candidatas, uma vez que ambos se agruparam no mesmo subgrupo do grupo II e há uma baixa distância genética entre estes genótipos ( $\mathrm{Dij}=0,022)$.

A candidata BAC 49 é a árvore mais velha entre as outras candidatas (plantio em dezembro de 1996), porém, não é a que apresenta maior valor de DAP. Enquanto que BAC 44, plantada dois anos após BAC 49 (plantio em janeiro de 1998), apresenta um DAP de $153 \mathrm{~cm}$.

O espaçamento do plantio adotado no talhão em que BAC 49 foi plantada é de 2 x 3 m enquanto que para BAC 44 adotou-se um espaçamento de 4 x $4 \mathrm{~m}$. Observa-se que o espaçamento de 4 x $4 \mathrm{~m}$ no plantio de teca, acarretou em um melhor desenvolvimento das árvores em relação ao DAP.

Os talhões 1 e 2 plantados em um espaçamento de $4 \times 4 \mathrm{~m}$ apresentam exemplares com altos valores de DAP, sendo, os talhões com a maior quantidade de candidatas selecionadas pelos produtores, seguidos pelos talhões 4, 6 e 13 com espaçamentos de $3 \times 3 \mathrm{~m}$. O talhão 9 foi representado apenas por BAC 49, uma vez que, o espaçamento deste talhão foi $2 \times 3 \mathrm{~m}$.

O espaçamento tem implicações em diversos fatores do ponto de vista silvicultural, tecnológico e econômico, tendo influência na qualidade da madeira, no ciclo de rotação, no manejo e exploração florestal (BALLONI, 1983). A teca é uma espécie heliófila que apresenta um aumento na mortalidade de plantas jovens quando a densidade de plantio é muito alta (PASSOS; BUFULIN; GONÇALVES, 2006). 
TABELA 5: Descrição dos valores fenotípicos de 50 genótipos selecionados de teca da fazenda Bacaerí Florestal.

TABLE 5: Description of selected phenotypic values of 50 genotypes teak the farm 'Bacaerí Florestal'.

\begin{tabular}{|c|c|c|c|c|c|c|c|c|c|}
\hline Genótipo & $\operatorname{DAP}(\mathrm{cm})$ & AT (m) & $\mathrm{AB}(\mathrm{m})$ & QR & QT1 & QT2 & QT3 & $\mathrm{FC}(\mathrm{cm})$ & FC (Nota) \\
\hline BAC 1 & 176 & 26 & 9 & 5 & 5 & 4 & 3 & 70 & 3 \\
\hline BAC 2 & 173 & 26 & 12 & 5 & 6 & 5 & 4 & 60 & 3 \\
\hline BAC $26^{*}$ & 124 & 22 & 18 & 5 & 5 & 5 & 5 & 0 & 6 \\
\hline BAC 27 & 104 & 22 & 14 & 3 & 4 & 4 & 3 & 40 & 3 \\
\hline BAC 28 & 121 & 22 & 6 & 3 & 5 & 5 & 4 & 0 & 6 \\
\hline BAC 29 & 138 & 22 & 8 & 3 & 2 & 3 & 2 & 60 & 3 \\
\hline BAC 30 & 104 & 22 & 12 & 4 & 2 & 3 & 2 & 0 & 6 \\
\hline BAC $31^{*}$ & 138 & 25 & 15 & 6 & 4 & 6 & 6 & 60 & 3 \\
\hline BAC 32 & 148 & 22 & 7 & 2 & 4 & 6 & 1 & 60 & 3 \\
\hline BAC 33 & 110 & 23 & 11 & 5 & 6 & 6 & 6 & 0 & 6 \\
\hline BAC $34^{*}$ & 140 & 24 & 8 & 3 & 4 & 6 & 2 & 0 & 6 \\
\hline BAC 35 & 137 & 23 & 8 & 3 & 4 & 6 & 2 & 70 & 2 \\
\hline BAC 36 & 123 & 20 & 7 & 0 & 4 & 5 & 1 & 0 & 6 \\
\hline BAC 37 & 130 & 22 & 7 & 2 & 4 & 6 & 1 & 80 & 2 \\
\hline BAC 38 & 146 & 22 & 6 & 1 & 4 & 5 & 1 & 100 & 1 \\
\hline BAC $39 *$ & 124 & 22 & 12 & 6 & 5 & 5 & 4 & 0 & 6 \\
\hline BAC 40 & 115 & 21 & 12 & 3 & 3 & 3 & 2 & 70 & 2 \\
\hline BAC 41 & 105 & 22 & 9 & 2 & 3 & 2 & 2 & 50 & 3 \\
\hline BAC 42 & 114 & 22 & 7 & 2 & 4 & 2 & 2 & 40 & 3 \\
\hline BAC 43 & 121 & 21 & 7 & 3 & 3 & 2 & 3 & 130 & 1 \\
\hline BAC $44 *$ & 153 & 21 & 9 & 4 & 6 & 6 & 5 & 0 & 6 \\
\hline BAC 45 & 116 & 21 & 9 & 2 & 5 & 4 & 1 & 0 & 6 \\
\hline BAC 46 & 122 & 21 & 9 & 4 & 6 & 4 & 2 & 0 & 6 \\
\hline BAC 47 & 118 & 21 & 8 & 5 & 3 & 3 & 2 & 30 & 4 \\
\hline BAC 48 & 118 & 21 & 8 & 2 & 3 & 2 & 1 & 0 & 6 \\
\hline BAC $49^{*}$ & 131 & 24 & 10 & 5 & 6 & 6 & 4 & 0 & 6 \\
\hline BAC $50^{*}$ & 133 & 22 & 12 & 3 & 5 & 5 & 4 & 0 & 6 \\
\hline BAC 51 & 123 & 22 & 10 & 3 & 3 & 3 & 2 & 40 & 3 \\
\hline BAC 52 & 107 & 22 & 11 & 5 & 4 & 3 & 2 & 40 & 3 \\
\hline BAC 53 & 111 & 22 & 8 & 4 & 5 & 3 & 2 & 0 & 6 \\
\hline BAC 54 & 124 & 22 & 10 & 3 & 4 & 3 & 3 & 0 & 6 \\
\hline BAC $55^{*}$ & 135 & 22 & 15 & 5 & 5 & 5 & 4 & 0 & 6 \\
\hline BAC 56 & 134 & 22 & 12 & 5 & 4 & 5 & 3 & 70 & 2 \\
\hline BAC 57 & 120 & 22 & 15 & 4 & 4 & 3 & 2 & 0 & 6 \\
\hline BAC 58 & 111 & 22 & 11 & 3 & 3 & 2 & 1 & 0 & 6 \\
\hline BAC 59 & 124 & 22 & 9 & 2 & 5 & 2 & 3 & 0 & 6 \\
\hline BAC $60 *$ & 128 & 22 & 7 & 3 & 5 & 4 & 3 & 0 & 6 \\
\hline BAC 61 & 102 & 20 & 7 & 2 & 2 & 4 & 1 & 50 & 3 \\
\hline BAC 62 & 125 & 20 & 6 & 3 & 4 & 5 & 2 & 0 & 6 \\
\hline BAC 63 & 98 & 19 & 6 & 2 & 3 & 3 & 2 & 0 & 6 \\
\hline BAC $65^{*}$ & 144 & 20 & 8 & 3 & 6 & 6 & 4 & 0 & 6 \\
\hline BAC 66 & 103 & 20 & 10 & 4 & 4 & 4 & 3 & 0 & 6 \\
\hline BAC 67 & 105 & 20 & 10 & 2 & 3 & 3 & 2 & 0 & 6 \\
\hline BAC 68 & 120 & 20 & 8 & 3 & 2 & 4 & 2 & 140 & 1 \\
\hline BAC 69 & 101 & 20 & 9 & 1 & 3 & 2 & 1 & 40 & 3 \\
\hline BAC $70 *$ & 136 & 24 & 9 & 4 & 4 & 6 & 4 & 0 & 6 \\
\hline BAC 71 & 112 & 24 & 10 & 2 & 5 & 3 & 1 & 0 & 6 \\
\hline BAC 72 & 115 & 24 & 11 & 6 & 5 & 4 & 4 & 0 & 6 \\
\hline BAC 73 & 101 & 24 & 8 & 4 & 4 & 3 & 2 & 0 & 6 \\
\hline BAC 74* & 116 & 24 & 10 & 5 & 6 & 6 & 4 & 0 & 6 \\
\hline
\end{tabular}

Em que: $\mathrm{DAP}=$ Diâmetro a altura do peito; $\mathrm{AT}=$ Altura Total; $\mathrm{AB}=$ Altura até a primeira bifurcação; $\mathrm{QR}=$ Qualidade dos Ramos; QT1, QT2, QT3 = Qualidade das Toras 1, 2 e 3; FC = Formação de Catana.* Árvores candidatas. 
TABELA 6: Autovalores ( $\lambda \mathrm{i}$ ), correspondentes às porcentagens de variação explicadas por Componentes Principais (CPi) e coeficientes de ponderação (autovetores) de 8 características fenotípicas, avaliadas em 50 genótipos de teca (Alta Floresta - MT, 2013) (SINGH, 1981).

TABLE 6: Eigenvalues $(\lambda i)$, corresponding to the percentage of variation explained by principal components (CPi) and the weightings (eigen vectors) of 08 phenotypic characteristics evaluated in 50 genotypes of teak (Alta Floresta, MT state, 2013) (SINGH, 1981).

\begin{tabular}{lccccccccccc}
\hline \multicolumn{1}{c}{ Autovalores } & \multicolumn{1}{c}{ Coeficiente de ponderação } \\
\hline CPi & $\lambda \mathrm{i}$ & \% Acumulado & DAP & AT & AB & QR & QT1 & QT2 & QT3 & FC \\
CP1 & 3,42 & 42,81 & 0,30 & 0,36 & 0,28 & 0,42 & 0,40 & 0,35 & 0,45 & 0,13 \\
CP2 & 1,45 & 60,92 & $-0,60$ & $-0,20$ & 0,42 & 0,24 & 0,00 & $-0,29$ & 0,16 & 0,51 \\
CP3 & 1,22 & 76,21 & 0,00 & $-0,28$ & $-0,44$ & $-0,30$ & 0,42 & 0,33 & $-0,04$ & 0,59 \\
CP4 & 0,64 & 84,21 & 0,02 & 0,69 & $-0,16$ & $-0,01$ & 0,22 & $-0,48$ & $-0,36$ & 0,28 \\
CP5 & 0,41 & 89,39 & 0,33 & $-0,06$ & 0,71 & $-0,47$ & 0,08 & 0,07 & $-0,35$ & 0,15 \\
CP6 & 0,36 & 93,86 & $-0,19$ & 0,31 & 0,00 & 0,17 & $-0,54$ & 0,60 & $-0,35$ & 0,26 \\
CP7 & 0,28 & 97,41 & 0,63 & $-0,30$ & $-0,09$ & 0,40 & $-0,35$ & $-0,28$ & $-0,06$ & 0,38 \\
CP8 & 0,21 & 100,0 & 0,09 & 0,27 & $-0,04$ & $-0,51$ & $-0,44$ & $-0,09$ & 0,62 & 0,24 \\
\hline
\end{tabular}

Em que: $\mathrm{DAP}=$ Diâmetro a altura do peito; $\mathrm{AT}=$ Altura total; $\mathrm{AB}=$ Altura até a primeira bifurcação; $\mathrm{QR}=$ Qualidade dos ramos; QT1, QT2, QT3 = Qualidade das toras 1, 2 e 3; FC = Formação de catana.

TABELA 7: Contribuição relativa das diversas características avaliadas para a divergência genética, em 50 genótipos de teca (Alta Floresta - MT, 2013) (SINGH, 1981).

TABLE 7: Relative contribution of the various characteristics valuated for genetic divergence in 50 genotypes of teak (Alta Floresta, MT state, 2013) (SINGH, 1981).

\begin{tabular}{|c|c|}
\hline Característica & Contribuição (\%) \\
\hline Diâmetro a altura do peito & 8,01 \\
\hline Altura até a primeira bifurcação & 8,11 \\
\hline Altura total & 8,20 \\
\hline Qualidade dos ramos & 8,98 \\
\hline Qualidade da tora 3 & 11,82 \\
\hline Qualidade da tora 1 & 13,66 \\
\hline Qualidade da tora 2 & 19,94 \\
\hline Formação de catana & 21,28 \\
\hline Total & 100,00 \\
\hline
\end{tabular}

Em média, segundo preceitos teóricos silviculturais, o espaçamento tem uma influência maior no desenvolvimento do DAP do que no desenvolvimento em altura das árvores (EVERT, 1971).

Quando se trata de um plantio comercial de teca, sendo o produto final a madeira, deseja-se uniformidade nos exemplares com relação ao fenótipo, principalmente em relação ao DAP e altura total. Diante disto, justifica-se a baixa diversidade do material avaliado.

\section{CONCLUSÕES}

Há diversidade genética entre os genótipos avaliados, sendo similar entre o grupo das candidatas e das árvores vizinhas às candidatas.

O método de agrupamento de UPGMA e Tocher formaram quantidade de grupos semelhantes e os genótipos mais distantes geneticamente foram BAC 54 e BAC 59. 
Com base nos dados fenotípicos, a variável formação de catana apresentou maior significância na representação da diversidade nos 50 acessos de teca e o maior espaçamento utilizado para o plantio possibilitou maiores valores de DAP.

\section{AGRADECIMENTOS}

À Fundação de Amparo à Pesquisa do Estado de Mato Grosso, pelo apoio financeiro concedido ao Projeto de extensão em interface com a pesquisa Processo No ${ }^{\circ}$. 213682/2012; à Coordenação de Aperfeiçoamento de Pessoal de Nível Superior - CAPES pela concessão de bolsas a primeira autora e a empresa Bacaerí Florestal pelo material fornecido.

\section{REFERÊNCIAS}

ASSOCIAÇÃO BRASILEIRA DE PRODUTORES DE FLORESTAS PLANTADAS. Anuário estatístico da Associação Brasileira dos produtos das florestas plantadas: ano base 2009. Brasília: ABRAF, 2009. $87 \mathrm{p}$.

ASSOCIAÇÃO BRASILEIRA DE PRODUTORES DE FLORESTAS PLANTADAS. Anuário estatístico da Associação Brasileira dos produtos das florestas plantadas: ano base 2011. Brasília: ABRAF, 2012. $149 \mathrm{p}$.

ALCÂNTARA, B. K.; SIQUEIRA, M. V. B. M.; VEASEY, E. A. Comparação de métodos de extração de DNA de teca (Tectona grandis L. f.) para estudos de caracterização genética usando SSR. In: CONGRESSO BRASILEIRO DE GENÉTICA, 54., 2008, Salvador. Anais.... [s. 1.: s. n.], 2008. p. 35.

ANSARI, S. A. et al. ISSR markers for analysis of molecular diversity and genetic structure of Indian teak (Tectona grandis L .f.) populations. Annals Forest Research, Romania, v. 55, n. 1, p. 11-23, 2012.

BALLONI, E. A. Influência do espaçamento de plantio na produtividade florestal. In: SIMPÓSIO IUFRO EM MELHORAMENTO GENÉTICO E PRODUTIVIDADE DE ESPÉCIES FLORESTAIS DE RÁPIDO CRESCIMENTO, 1983, São Paulo. Anais... São Paulo: [s. n.], 1983. p. 588-593.

BOTSTEIN, D. et al. Construction of a genetic linkage map in man using restriction fragment length polymorphisn. American Journal of Human Genetics, Amsterdam, v. 32, p. 314-331, 1980.

BRYNDUM, K.; HEDEGART, T. Pollination of teak (Tectona grandis Linn. F.) Silvae Genetica, Frankfurt, v. 28, p. 77-80, 1969.

CRUZ, C. D. Programa GENES: aplicativo computacional em genética e estatística. Viçosa, MG: UFV, 2008.

DOYLE, J. J.; DOYLE, J. L. Isolation of plant DNA from fresh tissue. Focus, Gaithesburg, v. 12, p. 13-15, 1990.

EVERT, F. Spacing studies: a review. Information Report, Ottawa, v.37, p.1-95, 1971.

FERREIRA, M. E.; GRATTAPAGLIA, D. Introdução ao uso de marcadores moleculares em análise genética. Brasília: EMBRAPA; CENARGEN, 1996. 220 p.

FIGUEIREDO, E. O. Reflorestamento com teca (Tectona grandis L. f.) no estado do Acre. Rio Branco: EMBRAPA, 2001. 28 p. (Documento, 65).

FONSECA, C. E. L.; RIBEIRO, J. F. Fruteiras do cerrado: estágio atual e perspectivas futuras. In: SIMPÓSIO NACIONAL DE RECURSOS GENÉTICOS DE FRUTEIRAS NATIVAS, 1., 1992, Cruz das Almas. Anais... Cruz das Almas: Embrapa; CNPMF; SBF, 1992. p. 63-75.

GILL, B. S.; BEDI, Y. S.; BIR, S. S. Cytopalynological studies in woody members of family Verbenaceae from north-west and central India. Journal of the Indian Botanical Society, Bangalore, v. 62, n. 1, p. 235-244, 1983.

HARTL, D. L. Princípios da genética de população. Ribeirão Preto: FUNPEC, 2008. 217 p.

HEDEGART, T. Pollination of teak (Tectona grandis Linn. f.). Silvae Genetica, Frankfurt, v. 22, n. 4, p. 124-128, 1973.

JOSÉBIO, R. L. G. M.; VENTURIM, N.; GOMES, B. G. S. E. Desenvolvimento em diferentes espaçamentos. Revista da Madeira, Curitiba, n. 106, p. 104-105, 2007.

KAOSA-ARD, A.; SUANGTHO, V.; KJAER, E. D. Experience from the improvement of teak in 
Thailand. Dinamarca: Danida Forest Seed Centre, 1998. 14 p.

KERTADIKARA, A. W. S.; PRAT, D. Genetic structure and mating system in teak (TectonagrandisL.f.) provenances. Silvae Genetica, Frankfurt, v. 44, n. 1, p. 2-3, 1995.

KJAER, E. D.; FOSTER, G. S. The economics of tree improvement of teak. Humlebeak: Danida Forest Seed Centre, 1996. 17 p.

MATHEW, G.; MATHEW, P. K.; MOHANADAS, K. Preliminary studies on insects visitors to teak (Tectona grandis L.f.) inflorescence in Kerala. Indian Forest, India, v. 113, n. 1, p. 61-64, 1987.

NARAYANAN C. et al. Optimization of DNA extraction for ISSR studies in Tectona grandisL. f. - an important forest tree species. African Journal of Biotechnology, Victoria Island, v. 5, n. 13, p. 1220-1223, jul. 2006.

PASSOS, C. A. M.; BUFULIN, L.; GONÇALVES, M. R. Avaliação silvicultural de Tectona grandis L.f em Cáceres - MT. Ciência Florestal, Santa Maria, v. 16, n. 2, p. 225-232, 2006.

REZENDE, R. K. S. et al. Divergência genética entre cultivares de gérbera utilizando marcadores RAPD. Ciência Rural, Santa Maria, v. 39, n. 8, nov. 2009.

RIBEIRO, I. C. N. S. Análise da divergência genética em acessos de Mangifera indica com base em descritores agro-morfológicos e marcadores microssatélites. 2011. 113 f. Dissertação (Mestrado) Universidade Estadual de Feira de Santana, Feira de Santana, 2011.

RONDON NETO, R. M.; MACEDO, R. L. G.; TSUKAMOTO-FILHO, A. A. Formação de povoamentos florestais com Tectona grandi sL.f. (Teca). Boletim Técnico - Série Extensão, v. 7, n. 33, p. 1-29, 1998.

SCHUHLI, G. S.; PALUDZYSZYN FILHO, E. O cenário da silvicultura de teca e perspectivas para o melhoramento genético. Pesquisa Florestal Brasileira, Colombo, v. 30, n. 63, p. 217-230, ago./out. 2010. SINGH, D. The relative importance of characters affecting genetic divergence. The Indian Journal of Genetics and Plant Breeding, New Delhi, v. 41, p. 237-245, 1981.

TSUKAMOTO-FILHO, A. A. et al. Análise econômica de um plantio de teca submetido a desbastes. Revista Árvore, Viçosa, MG, v. 27, n. 4, p. 487-494, 2003.

TROUP, R. S. The silviculture of India trees. Dehradum: [s. n.], 2006. v. 2, 1996 p.

UGALDE, L.; PÉREZ, O. Mean anual volume increment of selected industrial forest. [s. 1.]: FAO, 2001. Disponível em: <http://www.fao.org>. Acesso em: 20 dez. 2013.

VIEIRA, A. H. et al. Técnicas de produção de sementes florestais. Rio Branco: EMBRAPA, 2001. 4 p. (Documento, 205).

YEH, F.; YANG, R.; BOYLE, T. Popgene ver. 1.32: Microsoft Windows-based freeware for population genetic analysis. Quick User Guide, Canadá, 1999.

ZIETKIEWICZ, E.; RAJALSKI, A.; LABUDA, D. Genome fingerprinting by simple sequence repeat (SSR) - anchored polymerase chain reaction amplification. Genomics, San Diego, v. 20, p. 176-183, 1994. 